\title{
PENSAMENTO JUSPOLÍTICO LIBERAL: DESDOBRAMENTOS DA FILOSOFIA DE HAYEK E NOZICK E O DIREITO DE MORADIA
}

\section{LIBERAL JUSPOLITICAL THINKING: DEVELOPMENTS OF THE PHILOSOPHY OF HAYEK AND NOZICK AND THE RIGHT OF HOUSING}

\author{
Maurício Jorge Pereira da Mota $^{1}$ \\ Eric Santos Andrade ${ }^{2}$
}

\section{RESUMO}

Cuida-se de trabalho analítico-crítico que pretende questionar os pressupostos da visão liberal, em especial a de Friedrich Hayek e a de Robert Nozick, em relação aos direitos sociais como fontes de proteção da liberdade individual. Desenvolve-se a compreensão de Norberto Bobbio que filia a ideia de Direito Humanos à abstrativização e universalização de valores fundamentais que, por sua vez, são nada mais que a ressignificação da classificação dos direitos em gerações. Pretende-se discutir em que medida compete ao Estado perseguir os direitos sociais como direito, política ou prestação de serviços, e se de fato se está falando de uma competência que deslegitima o aparelho estatal. Para tanto, se construirá uma análise crítica dos fundamentos liberais em cima do direito de moradia e sua perspectiva no Brasil, em especial sob a leitura da Lei de Regularização Fundiária (Lei no 13.465 de 2017).

Palavras-chaves: Friedrich Hayek. Robert Nozick. Pensamento liberal. Direito a moradia. Direito fundamental.

\begin{abstract}
It deals with an analytical-critical work that intends to question the presuppositions of the liberal vision, in particular that of Friedrich Hayek and Robert Nozick, in relation to social rights as sources of protection for individual freedom. Norberto Bobbio's understanding is developed, which links the idea of Human Rights to the abstraction and universalization of fundamental values which, in turn, are nothing more than the redefinition of the classification of rights in generations. It is

\footnotetext{
${ }^{1}$ Professor do Mestrado e Doutorado em Direito da Universidade do Estado do Rio de Janeiro - UERJ, Professor do Doutorado em Meio Ambiente da Universidade do Estado do Rio de Janeiro - UERJ, Professor Adjunto da Universidade do Estado do Rio de Janeiro - UERJ e Procurador do Estado - Procuradoria Geral do Estado do Rio de Janeiro. Membro do Instituto dos Advogados Brasileiros - IAB. Afiliação:Universidade do Estado do Rio de Janeiro, UERJ Lattes: http://lattes.cnpq.br/8340543270360777. ORCID:https://orcid.org/0000-0002-9722-1330. E-mail:mjmota1@gmail.com

${ }^{2}$ Doutorando em Direito pela Universidade do Estado do Rio de Janeiro (UERJ). Mestre em Direito pela Universidade do Estado do Rio de Janeiro (UERJ). Membro da Rede de Pesquisa Interinstitucional em Direito da Cidade da Universidade do Estado do Rio de Janeiro (RPIDC/UERJ) e do Laboratório de Estudos de Direito Administrativo Comparado da Universidade Federal do Estado do Rio de Janeiro (LEDAC/UNIRIO). Membro da Comissão de Direito Administrativo e de Direito da Família e sucessões do Instituto dos Advogados Brasileiros (IAB). Membro do Instituto de Direito Administrativo do Estado do Rio de Janeiro (IDARJ). Advogado. Afiliação:Universidade do Estado do Rio de Janeiro, UERJ Lattes:http://lattes.cnpq.br/1295100572894793. ORCID:https://orcid.org/0000-0002-3857-0602. E-mail:ericsantos13@gmail.com
} 
intended to discuss to what extent it will be up to the State to pursue social rights as a right, policy or provision of services, and if in fact we are talking about a competence that delegitimizes the state apparatus. To this end, a critical analysis of the liberal foundations on the right to housing and its perspective in Brazil will be built, especially under the reading of the Land Regularization Law (Act $\mathrm{n}^{\circ} .13 .465$ of 2017).

Keywords: Friedrich Hayek. Robert Nozick. Liberal thinking. Right to housing. Fundamental right.

\section{INTRODUÇÃO}

A liberdade ou a falta de liberdade dos indivíduos não depende da gama de escolhas, mas da possibilidade de determinar sua conduta de acordo com suas pretensões correntes. Assim, liberdade pressupõe que o indivíduo tenha assegurada uma esfera privada, que exista certo conjunto de circunstâncias no qual outros não possam interferir.

Sob essa perspectiva de Liberdade é que se propõe discutir possíveis desdobramento da filosofia de Friedrich Hayek e Robert Nozick em razão do Direito de moradia, consagrado no art.

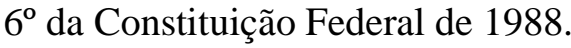

O Estado de Liberdade será primeiro compreendido sob o contexto da reduzida coerção que alguns exercem sobre os outros. É a chamada liberdade individual. A tarefa de uma política de liberdade, portanto, será o minimizar da coerção ou seus efeitos negativos. Logo, liberdade é coerção estarão intrinsecamente ligados no pensamento dos filósofos.

Contudo, no atual contexto socionormativo do pensamento filosófico, pauta-se o âmago do objetivo da busca pela liberdade a igualdade perante a lei. Para estes pensadores, a igualdade estabelecida pelas normas legais e de conduta gerais é a única forma de igualdade que conduz à liberdade e a única que podemos obter sem destruir a liberdade.

Sendo assim, será analisado as particularidades de cada sistema de pensamentos filosófico e, ao final, construir uma análise crítica do pensamento filosófico em relação aos direitos fundamentais como fonte medidor dessa igualdade jurídica, em especial o direito de moradia.

\section{PENSAMENTO LIBERAL E OS DIREITOS SOCIAIS:}

\subsection{FRIEDRICH HAYEK, OS FUNDAMENTOS DA LIBERDADE E O DIREITO:}

Friedrich Hayek e Robert Nozick representam dois dos marcos filosóficos mais evidentes no fundamental liberal dos EUA e constroem seu pensamento jusfilosófico com bases na individualidade do ser humano. Para tanto, será posto em debate seus fundamentos principais de 
seus pensamentos bem como o momento histórico no qual ambos visam desenvolver uma visão da sociedade mais justo e equilibrada.

Friedrich Hayek em sua obra Os Fundamentos da Liberdade toma como objetivo central mostrar que desde o século XIX os princípios da civilização ocidental estavam em ruína. Dentre eles, a liberdade, era cada vez menos respeitada (HAYEK, 1983, p. 33-35). Para o autor a iniciativa individual será o vetor que torna o homem um ser completo e realizado em si mesmo.

Naquele período houve uma grande preocupação com as crises de política econômica decorrente do sistema welfare state. Nos países ocidentais esses primeiros sinais decorriam de uma crise fiscal provocada pela incapacidade de se harmonizar os gastos públicos com o crescimento da economia. Como resposta, Friedrich Hayek mostrou uma grande preocupação com o dirigismo sistemático da política econômica do bem-estar social, mostrando que tudo se resumia na decadência dos princípios básicos da liberdade.

A liberdade passa então a ser entendida como um conceito universal e atemporal (HAYEK, 1983, p. 39). Ela passa a ser considerada não apenas um valor específico, mas uma condição para todos os valores morais dentro de uma sociedade. Hayek descreve o fundamento da liberdade como o basilar inicial para que o homem entenda o valor em si de cada ser individual. Desse entendimento, o homem compreende que a função de uma política de liberdade estará na possibilidade de se conviver em coletividade sem que haja um sistema que retire a sua individualidade.

Entender a liberdade para Hayek é ver que ele legitima e reconhece a necessidade de uma coerção social para restrição da liberdade, desde que ela seja mínima. Somente assim, Caridad Velarde diz que Hayek reconhece, posso entender o papel do Estado e do Direito (VELARD, 1994, p. 155). O papel do Estado será o de minimamente garantir a segurança social sem intervir sobre as escolhas individuais. O papel do Direito será primeiramente o de preservar os contratos e os acordos civilmente firmados, prestigiando sempre a volitividade das partes.

Friedrich Hayek mostra como característica da liberdade a adoção do seu conceito negativo que só se tornará positivo quando fizermos o uso dela (HAYEK, 1985, p. 234). Ela embora não nos assegure qualquer tipo de oportunidade, deixa a nosso critério a forma de se enxergar as circunstancias. A liberdade, assim, é uma só, embora seus sentidos possam ser descritos de maneira diversa.

A coerção é um elemento negativo dentro do pensamento de Hayek. Dela se postula a capacidade de conhecimento e de avaliação das coisas dos indivíduos, sendo um instrumento sob as mãos de terceiros. Reconhece que a coerção apesar de ser negativa é um mal inevitável dentro da sociedade (HAYEK, 1983, p. 61). Por isso, a coerção não pode ser completamente evitada, pois para isso deveria ser usada a própria coerção. A solução será, portanto, a entrega do monopólio da 
coerção ao Estado. Será o Governo quem protegerá as esferas individuais contra todas as outras interferências externas.

Entender o papel do Estado é necessário para delimitarmos os limites do pensamento de Hayek frente a concretização dos direitos sociais, vistos até então como uma péssima gestão diante da crise do sistema de bem-estar social. Para isso, a sociedade passa a ser compreendida sobre uma visão de superação histórica. O homem ao adquirir conhecimento ele o transmite para as futuras gerações, até chegarmos ao ponto daquele conhecimento adquirido estar cada vez mais especializado $^{3}$. Nessa medida, ao forçar e permitir que o homem corra riscos eu legitimo o avanço da civilização. A liberdade individual fundamenta-se no reconhecimento da ignorância dos homens. Não haveria razão para se defender a liberdade se já se conhecesse tudo. A liberdade é essencial, deste modo, para que o imprevisto exista.

A liberdade significa, então, renunciar o controle dos esforços individuais de uma sociedade livre que pode usar muito mais conhecimento quando faz parte de um todo harmônico. Friedrich Hayek não deixa de entender a ideia de que a liberdade está associada a aspirações de indivíduos que não são limitadas, pois o esforço de um individuo pode, posteriormente, ser adotado pela maioria. As inspirações individuais auxiliam na perpetuação das ideias dos grupos que poderão continuar as mesmas, ou sofrer mudanças (VELARD, 1994, p. 181).

É dizer que todos os homens não podem ser considerados iguais, sendo um pressuposto enganoso. Liberdade e igualdade não têm relação, sendo que o reconhecimento da liberdade individual leva a produção de desigualdades. A igualdade vista por Hayek vai ter ligação direta com o exercício do Direito, sendo que ela terá a função de assegurar o tratamento isonômico entre pessoas diferentes quando sobre a lei (VELARD, 1994, p. 183).

Hayek explora melhor o tema da liberdade e da lei no capítulo 05 da sua obra Direito, Legislação e Liberdade (HAYEK, 1985, p. 247). O juiz, sendo a representação do aplicador do Direito, são reconhecidos como uma instituição que tem deve se aproximar do ideal da ordem liberal. O Direito representa uma nova ordem espontânea, ou seja, uma sistemática totalmente distante de uma condução obrigatória de deveres sociais.

Direito não deriva da autoridade, a lei é pré-existente à sociedade. O Direito será condição imprescindível para a formação da sociedade, sendo que ele preexiste a sua gênese. A lei não será o conteúdo proveniente da elaboração do Poder Legislativo, está para além disso. Interessa saber a observância factual que leva a formação de uma ordem de ações (lei), enquanto que a sua aplicação ou não constitui um interesse secundário.

\footnotetext{
${ }^{3} \mathrm{O}$ progresso assim, depende de um máximo de oportunidades para que as coisas aconteçam. As instituições da liberdade são, portanto, adaptações à ignorância para que seja possível lidar com todas as possibilidades. Para mais informações, ver: HAYEK, Friedrich A. Os fundamentos da liberdade. São Paulo: Visão, 1983, p. 91
} 
Todavia, o aparelho jurídico no pensamento de Hayek nasce com o objetivo de assegurar e aperfeiçoar um sistema de normas já pré-existente (ordem global) (HAYEK, 1997, p. 16). Aqui o julgamento não visa discutir se as partes obedeceram ou não a vontade de alguém, mas se as ações corresponderam a expectativa que se tinha pela conduta cotidiana dos membros do grupo. Os costumes ganham importância. A satisfação do que ele denomina como "expectativas" não diz que alguém vai estar obedecendo a vontade de alguém, mas sim de algo que é esperado por toda coletividade ou grupo. Se for preciso se socorrer a um juiz imparcial é porque ele fará cumprir o costume, ou seja, aquilo esperado por qualquer pessoa em posição semelhante.

A finalidade precípua do Direito para Hayek é de manter a paz (VELARD, 1994, p. 149-204). O conceito de paz é da manutenção de uma ordem vigente de ações já esperadas. A norma jurídica terá como objetivo a facilitação da correspondência dessas expectativas, sendo somente necessária quando houver uma quebra dessa correspondência. Assim, pode-se concluir que Hayek adota um verdadeiro conceito negativo do Direito frente ao seu papel de mantenedor da liberdade individual.

Normas de conduta justas serão aquelas que que prestigiam a avaliação da progressão dos costumes. Assim, o autor considera que o Direito estará sempre em um constante movimento de aperfeiçoamento pelos juízes, sendo não uma sistemática de imposição autoritária de ações, mas de uma observação de toda uma ordem global pré-existente.

Os juízes não possuem a liberdade para proferir a norma que lhes aprouver. Hayek explica que sua condução deve nortear as lacunas das legislações vigentes, de maneira que possam servir à manutenção e ao aprimoramento da ordem de ações já existentes (HAYEK, 1983, p. 124-126). O autor considera que qualquer pressuposto que leve os juízes a decidirem para além da manutenção dessa ordem global de liberdade os fará agir não pela razão, mas por meio de preferência emocionais ou pessoais, sua compaixão pela dificuldade de um dos litigantes, ou sua opinião sobre a importância de um objetivo particular, acabando por influenciar a sua decisão final. Comprometese a manutenção da paz pela violação da liberdade individual.

Ao perpassarmos o entendimento do autor sobre os direitos sociais, pode-se dizer que a sua concretização não deve ser elemento integrando do conceito de liberdade e da ordem global. Não há por meio da concretização dos direitos sociais um prestígio pelo risco que cada indivíduo deve assumir sobre suas capacidades, sendo que o Estado e o Direito estariam prestigiando certos indivíduos em detrimento de outros. Chega-se a conclusão de que não haverá o progresso civilizatório que se espera e, consequentemente, incorre na eclosão de crises de ordem juspolítica e financeira (HAYEK, 1983, p. 128).

O propósito do Direito será o de não servir a nenhum propósito em particular, mas sim o de considerar inúmeros diferentes propósitos de diferentes indivíduos. Ele provê apenas os meios para a consecução de um grande número de diferentes propósitos que, em sua totalidade, ninguém 
conhece. Entre todos os instrumentos polivalentes, o Direito é, provavelmente, depois da linguagem, aquele que auxilia a maior variedade de propósitos humanos (HAYEK, 1997, p. 12).

Assim, o problema dos direitos sociais para Hayek vai estar na advertência de que há certos valores aceitos que não são aqueles valores que norteiam as ações dos diversos indivíduos. $\mathrm{O}$ autor discorda do entendimento de que o objetivo do Direito será o de atribuir a cada um o que lhe é devido, atribuindo a cada indivíduo determinadas coisas (HAYEK, 1983, p. 131). Tudo que se afasta da premissa unidirecional de traçar limites para que as ações de diferentes indivíduos não interfiram umas nas outras constitui forma de cercear o exercício da liberdade.

Como a liberdade não pressuporá a igualdade, pois ela legitima a desigualdade como uma desviturde necessária ao progresso da civilização, entende-se que haverão expectativas que podem ser protegidas e outras não. Algumas precisam ser protegidas a fim de se maximizar a possibilidade de as expectativas em geral serem satisfeitas. Existem as expectativas legítimas, que o Direito deve proteger, e outras, que ele deve permitir que se frustrem.

Portanto, não são todas as expectativas que serão protegidas pelas normas gerais. $\mathrm{O}$ autor reconhece que nem sempre é vantajoso impedir todas as ações que possam prejudicar alguém. $\mathrm{E}$ essa será sua justificativa frente aos direitos sócias, pois é legitimar ao Estado agir de forma autoritária, retirando o poder decisórios dos indivíduos, da sua capacidade, da necessária assunção dos riscos sociais indispensáveis ao progresso da civilização. A função única da lei será o de impedir que ações de certos indivíduos afetem outros. Como as leis não são capazes de prever todas as hipóteses, é papel dos juízes confrontá-las com os litígios sociais (VELARD, 1994, p. 155-157). Então, temos uma correspondência harmônica entre o papel exercido pelo Direito, pelos juízes e pelo Estado na confrontação da liberdade individual como justificação de uma sociedade justa.

Poder se afirmar que para Friedrich Hayek a concretização dos direitos sociais não tem parte na tríade juiz, Estado e Direito. Isso porque direitos que demandam ações positivas partem do pressuposto do autoritarismo governamental. O planejamento de uma pré-ordenação de ações dentro da civilização é criar obstáculos às expectativas dentro de uma ordem espontânea.

É o que o autor considera como ativismo da justiça social. Ela não tem aplicação em uma sociedade de homens livres. Pode-se dizer que a justiça social apenas ganhou destaque ao longo dos tempos por reivindicações de grupos particulares que buscaram ter uma maior participação em coisas boas da vida, desrespeitando a livre iniciativa global e interferindo na liberdade individual de outras pessoas que se valeram da sua capacidade e assumiram riscos para alcançar seus objetivos (HAYEK, 1997, p. 18).

Essa é a crítica que o autor faz contra o conceito de justiça distributiva, como a redistribuição de bens e serviços na sociedade. E ainda assevera Friedrich Hayek que viver em sociedade é aceitar além as desigualdades que haverão pessoas insatisfeitas com o sistema de distribuição existente. Ao 
mesmo tempo elas não sabem o que é justiça, pois ao reclamarem a redistribuição de bens e serviços para si em detrimento de outras pessoas, sem haver qualquer justo motivo que as torne superiores em relação a propriedade das capacidades, geram na civilização uma desigualdade social flagrante e compromete os recursos públicos que explodirão em crises de política econômica (HAYEK, 1983, p. 144).

Nessa medida, critica o modelo socialista por representar uma revolta contra a justiça imparcial, que considera apenas a conformidade de ações individuais a normas independentes de fins, sem levar em conta os efeitos da aplicação destas a casos particulares. Por isso, para o Direito ser considerado justo ele deve assegurar uma aplicação universal e abstrata e não destinada a um grupo ou grupos que estariam sendo privilegiados, o que violaria a igualdade formal das leis.

Em última análise, a diferença entre as normas de conduta justa que emergem do processo judicial e as normas organizacionais estabelecidas pela autoridade, que examinaremos no próximo tópico com Robert Nozick, reside no fato de que as primeiras derivam das condições de uma ordem espontânea não criada pelo homem, enquanto as segundas servem à construção intencional de uma organização que atende a propósitos específicos, violando expectativas legítimas.

O Estado tem como único papel o dever de prevenção e controle de ações contrárias à ordem, se pensarmos acerca da função do Direito em Hayek. A ideia de norma justo é antagônica a comportamentos construtivistas, que é a proposta do Estado do bem-estar social que está na igualdade de oportunidades pela intervenção do Governo. A justiça nunca estará na predeterminação de ações dentro da civilização, mas na proteção de toda uma ordem espontânea de expectativas criadas livremente pela sociedade, devendo o Estado garantir minimamente por meio de leis a segurança do exercício dessa liberdade individual sem que esteja à mercê da interferência de interesses de terceiros.

\subsection{ROBERT NOZICK E O PAPEL DO ESTADO FRENTE AOS DIREITOS POSITIVOS:}

Robert Nozick tem como obra fundamental do seu pensamento jusfilosófico de civilização o ensaio Anarquia, Estado e Utopia (1974) (NOZICK, 2011, p. 199). Neste tópico se pretende explorar os pressupostos da figura do Estado mínimo frente aos direitos sociais.

A crítica de Nozick, assim como de Hayek, é direcionada ao Welfare State, coincidindo com o momento da sua crise nas sociedades democráticas ocidentais. $\quad \mathrm{O}$ autor se vale dos pressupostos de John Locke para trazer a concepção de que cada indivíduo é dono de si. Cada um está dotado naturalmente de liberdade para dispor de si próprio e de seus bens como bem entender, porque parte-se do pressuposto de que foram adquiridos com os esforços do próprio trabalho, da 
propriedade. Nisto vai consistir os limites da atuação do Estado, na medida em que ele intervém no corpo ou nos bens individuais ele está excedendo suas funções (WOLFF, 1991, p. 14-15).

Mas que funções são essas? Para responder essa pergunta é preciso considerar que a ensaio de Robert Nozick é uma resposta à obra Justiça Distributiva de John Rawls. O que faz constituir atualmente uma sociedade justa não é a igualdade social das pessoas, como é defendido por meio do pensamento de John Rawls, pois a igualdade não pressupõe a liberdade, assim como defende Friedrich Hayek. Nozick esclarece que para alcançar a igualdade Rawls precisa sustentar um Estado intervencionista na vida privada das pessoas, o que lhes retira a liberdade de tomar suas próprias decisões. Na anarquia Nozick vê claramente que a liberdade total também dá margens a desigualdade, o que dá margem à injustiça.

O grande destaque de Robert Nozick está na singularidade das funções do Estado em sociedade. O título da sua obra está divido em três partes. A primeira, que diz respeito à anarquia, Nozick vai sustentar que não é bom que haja exclusão da figura estatal, na medida em que ela será imprescindível e necessária para assegurar a liberdade individual, sendo que a sua gênese é um processo inevitável. Conforme Thomas Scanlon, na medida em que o homem se associa se torna comum os litígios e cresce a necessidade de segurança. As associações serão um caminho para a formação do Estado vez que por meio delas os indivíduos criam minimamente mecanismos para proteger os seus bens (SCALON, 1981, p. 109-110).

Observa-se que a figura do Estado é reconhecida como um mal à civilização. Contudo, ela será um mal necessário. A grande questão está em saber medir os parâmetros do que tornará ele legítimo. A sua filosofia é muito forte na defesa inviolável dos direitos do indivíduo, como o direito à vida, a liberdade, a propriedade (entendida não apenas como bens móveis ou imóveis, mas também o próprio corpo, as ideias, o pensamento), a não coerção. São exemplos de direitos invioláveis e que concernem esses direitos naturais de todo e qualquer indivíduo.

Segundo, a utopia diz respeito à figura do Estado intervencionista de John Rawls, na medida em que falarmos em uma justa distribuição de bens e serviços seria algo intangível no plano prático. Para tanto, bastaríamos ver as crises socioeconômicas do estado de bem-estar social. Sendo assim, a terceira e última figura é o Estado que está centralizado no meio do título da obra de Nozick.

Nozick pretende reforçar a ideia do Estado mínimo como algo que não será frágil e nem deixaria a desejar, pois qualquer aumento de sua força resultaria na assimetria de direitos entre o Estado e o indivíduo (NOZICK, 2011, p. 210). Também um Estado com mais poder além do necessário certamente o fará ir além da sua função legítima de defesa. Nozick demonstra uma preocupação moral e ética com o exercício da liberdade como também uma preocupação política relativa ao exercício dessa liberdade. É a partir deste ponto que ele reforça a figura do Estado mínimo. 
Para compreender os efeitos dos direitos sociais no Estado mínimo de Robert Nozick será preciso destrinchar os seus pressupostos de Direito. O autor acredita que as pessoas de uma sociedade justa desejarão ser compensadas pelo benefício prestado, e isso leva indistintamente às relações de competição entre indivíduos. Como consequência, o preço de mercado dos benefícios seria inferior ao preço mais alto que o beneficiário estaria disposto a pagar, e esse superávit em favor dos consumidores representaria o benefício de viver em sociedade livre.

É um equivoco considerar que Nozick não é partidário de um Estado Democrático. O Estado mínimo é a representação do Estado Democrático, pois não haveria violação de direitos individuais de quem ser que seja. Nessa medida, a civilização de Nozick será aquela que garanta o mínimo existencial digno para todas as pessoas, e que todo mundo deva ter as mesmas oportunidades de vencer na vida (NOZICK, 2011, p. 287-288).

Importante considerar que Robert Nozick não é um liberal, mas um libertário. Nesse viés, importa saber que sua concepção geral de liberdade alcança todas as searas da vida do homem, não se restringindo a matéria econômica e da liberdade do mercado. Envolve um partido de liberdade sobre o ser como um todo, seu corpo, sua mente, suas crenças, seus desejos etc.

Assim, pode-se afirmar que sua filosofia vai de encontro até mesmo com o utilitarismo. Tratase da ideia de que o bem maior é proporcionar a maior felicidade possível para o maior número de indivíduos, mesmo que para isso seja preciso sacrificar uma minoria. Para o autor esse pensamento é inconcebível, rejeitando completamente essa posição (POGREBINSKI; FERES JÚNIOR, 2010, p. 56-69). Afinal, é papel do Estado garantir a todos, sem exceção, a proteção da sua liberdade e não apenas em detrimento de um grupo maior.

Os direitos considerados invioláveis serão todos aqueles que já possuímos antes mesmo de nos considerarmos parte de uma civilização. É o que o autor denomina como estado de natureza. No Estado de natureza ele se vale das concepções de John Locke no qual todos éramos livres e comercializávamos entre si (LACEY, 2001, p. 26). Só que havia um problema: não havia uma entidade para julgar os conflitos com imparcialidade e, portanto, não se sabia o que seria um julgamento considerado justo. Desta premissa vem a classificação de insegurança jurídica do filósofo inglês. Por isso Locke diz haver a necessidade de se criar um ente com autoridade suficiente para trazer a justiça imparcial, garantindo um mínimo de segurança jurídica.

Entretanto, diferente de John Locke que será considerado um contratualista, vez que a criação do Estado se dará por meio de um pacto social ou contrato social, Robert Nozick vai ressignificar a sua filosofia ao considerar elementos da antropologia. O Estado é criado de forma espontânea, na medida em que as pessoas se juntam para criarem as associações de proteção (NOZICK, 2011, p. 324-325). Elas protegem os indivíduos da violência de outros indivíduos que não fazem parte das associações, servindo inicialmente para julgar os conflitos de forma imparcial e justa. 
Para Nozick essas associações de proteção não são a representação da figura do Estado ainda, vez que ainda demandam uma complexa organização que não era possível naquele momento originário. Porém, o fato das pessoas inevitavelmente criarem essas associações afasta qualquer fundamento anarquista, pois como dito anteriormente a organização do Estado será um pressuposto indispensável para a convivência em sociedade.

Contudo, não se está falando apenas de uma associação de proteção, mas de várias que coexistem no tempo e no espaço. Chegando ao momento de que naturalmente haverão associações que cresceram tanto que dominaram toda uma região geopolítica, pois o número de associados crescerá vez que as pessoas irão desejar ter uma proteção mais especializada. O que antes existiam simples associações onde os indivíduos se ajudavam mutuamente, essas associações especializadas demandaram uma organização mais complexa bem como a contraprestação de bens ou serviços dos seus usuários para passarem apenas a condição de beneficiários da prestação de serviços de proteção destes agentes. É o que Nozick denomina como sendo o surgimento do Estado ultra mínimo que dará origem ao Estado mínimo (NOZICK, 2011, p. 358).

O Estado mínimo será o único Estado moralmente legítimo, pois não violará os direitos individuais visto que originariamente as associações de proteção e sua evolução se centraram não no controle das pessoas, mas sim na abstenção de uma violação da liberdade individual (NOZICK, 2011, p. 367). Será um Estado que protegerá os indivíduos da violência de outros indivíduos, protege do roubo, da fraude e garante a execução dos contratos.

Assim, os direitos sociais passam a ser desconsiderados no pensamento de Robert Nozick, pois faz com que o Estado venha a assumir mais funções dos que aquelas que minimamente ele deveria ter. O Estado não teria nenhum dever de garantir saúde, lazer, educação, previdência social, transporte etc. Em sua visão nem ao menos os direitos sociais são considerados como direitos, mas sim como prestação de serviços (LACEY, 2001, 31-32).

Os serviços constituem aqueles nos quais cada um deve correr atrás para que deles possam usufruir. Questiona-se se o que acontecerá se todos os serviços no final forem lançados sobre a responsabilidade do Estado quem terá de arcar com os custos do seu benefício diretamente? O próprio Estado, significando em além de um encarecimento da vida civil uma violação direta à liberdade individual e à isonomia. Trata-se de uma forte crítica que Nozick faz à Rawls, pois o Estado não dispõe de recursos para arcar com estes serviços à toda a sociedade.

A lógica de Nozick advém de que para o Estado prestar esses serviços inevitavelmente terá que tirar recursos daqueles indivíduos que o possuem para dar a quem não possua. Isso, na visão da teoria filosófica de Nozick, é ilegítimo, pois segue bases de justiça distributiva de Rawls. Não se pode legitimar o uso de um indivíduo como fonte de recursos para outro indivíduo considerado menos favorecido, muito embora ambos estejam partindo da mesma posição de liberdade. Nozick 
retoma a filosofia de Kant e afirmar que cada indivíduo deve ser considerado um fim em si mesmo (NOZICK, 2011, p. 7). A sua máxima é esta: ninguém pode ser sacrificado em favor de outrem.

Para exemplificar seu pensamento Nozick se socorre aos impostos. Não poderia, nesse exemplo, o Estado confiscar a sua propriedade para dar a outros indivíduos menos favorecidos, visando a igualdade. Com isso o Estado se torna ilegítimo e assim perde a sua razão de ser. Portanto, pode-se dizer que a liberdade dos indivíduos é o que exerce o papel central de limitação, o que seria viável e o que é considerado legítimo em termos de atuação do Estado. Não há dentre as funções estatais a de assegurar a efetivação de direitos sociais.

O traço marcante da filosofia de Nozick, segundo John Exdell, está na afirmação de que essa liberdade e esses direitos restringem o que pode ser feito em termos de justiça e em termos de atuação do Estado (EXDELL, 1977, p. 143). A justiça será nada mais que o respeito a liberdade original e à propriedade de si mesmo e sobre a propriedade de coisas que os indivíduos adquiriram ao longo da história de forma legítima.

Assim, ele mostra ao longo da sua obra que os direitos e as liberdades são classificados como de natureza constitutivas, ou seja, resultantes de um acordo ou de um contrato. E isso importa na medida em que os direitos sociais não pertencem a classificação constitutiva, mas sendo qualificadas como de natureza deliberativa, o que não é legítimo de permear as funções do Estado.

O Estado de Nozick tem algumas características que podem ser delimitadas: i) o Estado reivindica o monopólio de decidir quem pode usar a força e quanto pode usa-la; ii) o Estado afirma que só ele pode decidir em quem vai usar o força e em que condições; iii) o Estado reserva-se do direito exclusivo de transferir a legitimidade e a permissibilidade de qualquer uso da força dentro de suas fronteiras (no estado moderno é o que acontece quando se transfere para os soldados, policiais, agentes de segurança etc.); iv) o Estado afirma ter o direito de punir todos aqueles que violarem o monopólio da força por ele reivindicado.

Robert Nozick vai estabelecer diferenças entre o Estado mínimo e o Estado ultra mínimo: i) O Estado mínimo será o Estado que assume para sai a função de proteger a todos contra violência, roubo, fraude etc., e por isso cobra de todos impostos; ii) O Estado ultra mínimo será aquele no qual os que optam por pagar pela contribuição estarão protegidos. Para o Nozick aquelas associações de proteção vão gerar primeiro o Estado ultra mínimo para depois se qualificarem como Estado mínimo (WOLFF, 1991, p. 37-38).

Nesse ponto, o Estado mínimo pode se configurar como redistributivo, porque os indivíduos com mais posses pagam para financiar a proteção dispensada aos que não podem pagar por ela. Todavia, financiar os benefícios de uns em detrimentos do exclusivo ônus sobre outros não é considerado ilegítimo para Nozick? O autor vai responder que essa redistribuição é apenas uma aparência, a justificativa estará na sua adoção do conceito de Direito. 
O Direito a ser adotado deverá sempre ser o da concepção negativa, ou seja, parte-se de uma ideia de abstenção e não de prestação. Ao abordarmos o direito à vida como um direito individual inviolável podemos visualiza-lo tanto sob uma concepção positiva quanto negativa de direito. Se positiva é dizer que por meio do direito à vida o Estado deve proporcionar à sociedade tudo que ela necessita para sobreviver, como alimentos, saúde, educação, etc. Por meio da concepção negativa do direito à vida o Estado não teria nenhuma obrigação frente a sociedade, mas tão somente o de garantir que todos os demais se abstenham de colocar me risco o meu direito, como tentativa de assassinato por exemplo.

Assim, os direitos para Nozick são negativos, e eles servem como restrições indiretas. E eles são mais importantes que todas as demais considerações morais. A proteção que se oferece a todos em um dado território se justifica na manutenção das restrições indiretas, não como elemento que visa aumentar o bem-estar geral, ou que visa minimizar a violação dos direitos, ou ampliar o número total de direitos em uma visão utilitarista.

\section{DIREITOS FUNDAMENTAIS, POLÍTICA OU SERVIÇOS?}

Considerando os pressupostos de cada um dos pensadores liberais acima conclui-se que os direitos sociais são distinguidos de todo o arcabouço dos direitos considerados fundamentais (direito natural), vez que não integrantes de uma ordem espontânea demandam uma prestação positiva pelo Estado. Todavia, o reconhecimento desta atribuição torna ilegítimo o atuar estatal e a coparticipação do Direito na tutela destes interesses, vez que os direitos sociais sequer chegam a ser considerados direitos propriamente dito, mas prestação de serviços.

Nesse sentido, neste tópico não será destrinchado em que medida os direitos sociais, chamando aqui atenção em especial ao direito de moradia, são tão importantes quanto a liberdade individual para assegurar a igualdade. Será o objetivo contornar as limitações do pensamento liberal frente aos pressupostos por eles mesmos adotados como fundamentos de um Estado mínimo.

Questiona-se em que medida os direitos sociais teriam natureza de direitos fundamentais ou de serviços. Consoante o entendimento dos pensadores liberais, são estas as ponderações a serem analisadas: 1) direitos sociais demandam prestações positivas; 2) direitos sociais importam na desigualdade do trato perante as leis; 3 ) possuem natureza de prestação de serviços.

\subsection{CONCEITO POSITIVO DE DIREITOS SOCIAIS:}

O conceito positivo de direito social é o âmago da justificativa de Robert Nozick para afastar a ideia de que o Estado mínimo pode ser criticado por se mostrar como redistributivo. O conceito 
negativo de direito é reconhecido como a qualidade dos direitos fundamentais que estarão privilegiando a liberdade individual e, ao mesmo tempo, assegurando a igualdade.

A construção da ideia de direito sociais está diretamente arraigada com o fim da $2^{\circ}$ Guerra Mundial e o marco constitucional do caráter intervencionista do Estado no âmbito social e econômico, com a Constituição Mexicana de 1917 e a de Weimar de 1919. Os pensadores partem da concepção de que ao impor funções sociais às competências do Estado eu necessariamente estaria trabalhando com a ideia de utilitarismo de direito (NOZICK, 2011, p. 19). Nesse sentido, o utilitarismo de direito nesse contexto estaria em uma espécie de maximização da segurança jurídica em detrimento da liberdade.

Ao abordar o direito de moradia, reconhecido como direito de natureza social, seria afirmar que este direito pode tanto partir de uma concepção negativa quanto positiva. Sendo assim, a concepção negativa do direito de moradia muito chama atenção, pois em certa medida se confunde com a concepção de outro direito extremamente tutelado pelo pensamento libertário: o direito de propriedade (ROLNIK, 1999, p. 41).

Tratando de uma concepção negativa afirmar-se que o direito de moradia seria a proteção do Estado necessária para que os indivíduos possam ter o exercício da moradia assegurada sem a interferência de terceiros. Moradia e propriedade são dois conceitos que sempre foram confundidos, ao ponto da moradia vir a ser representada mais como um efeito advindo da proteção do direito de propriedade.

As políticas habitacionais no Brasil refletem com clareza a confusão. Em resposta ao flagrante déficit de moradia que dificultava a organização e gestão das cidades em crescimento o Estado criou o Banco Nacional de Habitação em 1964 (NASCIMENTO, 2013, p. 36). Surge com o propósito de financiar empreendimentos imobiliários e promover o desenvolvimento urbano de moradias no país.

Todavia, o fim do BNH em 1986 deu-se por alguns principais motivos: inadimplência; corrupção e; sobretudo, o Sistema Financeiro da Habitação não conseguiu ser capaz de atingir a principal demanda do déficit de habitação do país - aqueles com renda inferior a 5(cinco) salários mínimos (NASCIMENTO, 2013, p. 38).

Sob a perspectiva do pensamento liberal a crise do BNH seria justificada pela ausência de recursos públicos suficientes para o atendimento de uma demanda de um grupo especial de indivíduos. Todavia, a proposta do BNH nunca esteve centrada na moradia, mas sim na mercantilização do direito de propriedade.

O tão divulgado "sonho da casa própria", bastante alimentada nos anos 80-90, repercutiu de forma evidente na mercantilização da moradia, sob a forma de propriedade. Ou seja, você visualiza o direito de morar como efeito do exercício da propriedade do imóvel. O fracasso do BNH deu-se 
também não por ser incapaz de resolver o problema do déficit de moradia, mas sim por mascarar uma produção mercantil de propriedades que acabavam atendendo apenas interesses de indivíduos que não estavam enquadrados nos grupos prioritários de atendimento.

Nessa linha, a construção e mercantilização de direitos de propriedade pelo Estado estaria dentro da concepção positiva de um direito fundamental de liberdade para os pensadores. Por ser assim, se sustenta que a mera concepção negativa do direito acaba sendo insuficiente para assegurar a liberdade individual.

Fato é que o BNH nunca foi verdadeiramente um programa de moradia social, mas de capitalização de recursos para produção de propriedades. O que se discute é que necessariamente o modelo liberal importa a intervenção estatal em certa medida, seja ela no social, ou seja ela no âmbito econômico (MALUF, 2011/2012, p. 845).

Abordar a concepção positiva não necessariamente será vista como a justificativa para a incapacidade do Estado de assumir uma função natural. É dizer que as concepções negativas nunca gerarão custos, o que é um equívoco. A manutenção da segurança às propriedades individuais demanda todo o manejo de recursos públicos para o custeio de pessoal, de objetos de serviços, de infraestrutura etc.

Isso leva a ressignificação da compreensão dos direitos fundamentais e sua concepção. Segundo Mariana Chiesa os direitos fundamentais possuem uma própria identidade, não podendo aqui ser dividido ou suprimido. Nesse viés, se está superando a subdivisão de conceito negativo e positivo de direito para uma ideia de direito fundamental (NASCIMENTO, 2013, p. 81).

Em outra medida, se torna questionável o papel do Estado mínimo, pois a sua limitação meramente a concepção negativa de direito mostra a ausência de um controle sobre a garantia da liberdade individual, vez que haverá indivíduos que por conta de peculiaridades sociais e históricas não conseguirão exercer o seu direito de moradia e, consequentemente, não terá resguardada a sua liberdade individual. É o defendido por Aldo Francisco Migot no qual o direito de moradia é nada mais que a porta para todo e qualquer indivíduo possa exercer todos os demais direitos considerados de $1^{\circ}$ geração (MIGOT, 2033, p. 90).

Ressignificar o direito de moradia dentro do contexto acima revela a necessidade de se superar a subdivisão de direitos positivos e negativos para uma interpretação única: direitos fundamentais. São considerados direitos fundamentais aqueles nos quais ao Estado cabe o dever tanto de observar, de forma a impedir que terceiros violem o seu direito, como também o de fazer cumprir, na medida em que por ser fundamental é assegurado a todo e qualquer indivíduo.

Observa-se que a justificativa está em assegurar a igualdade, vez que de forma inevitável haverá de se superar a ideia do utilitarismo de direito. Na medida em que os pensadores confessam que o pagamento de tributo ao Estado para financiar a proteção estamos diante de uma realidade 
redistributiva de qualquer forma. Haverá indivíduos com mais posses pagando pela proteção que será dispensada aos que não podem por ela pagar. Entender esse contexto, mesmo que embora sob uma concepção negativa, não afasta que a igualdade no exercício da liberdade está sendo garantida a uns em detrimento de outros.

Os direitos sociais, assim como o direito de moradia, podem se mostrar como concepções positivas de direito. Contudo, o pensamento liberal não consegue negar que sempre haverá na concepção negativa de direito um viés redistributivo mínimo considerado, pois ao reconhecer a desigualdade social está assumindo o ônus de estar financiando serviços de proteção àqueles que não podem por ela arcar (FUKASSAWA, 2013, p. 181).

O direito de moradia é uma forte representação da ideia de garantir a individualidade de cada ser. Há uma superação da ideia de direitos de $1^{\circ}$ e $2^{\circ}$ geração, pois acabam que todos eles se confundem de certa maneira na promoção do bem individual (FUKASSAWA, 2013, p. 187). E na medida em que eu asseguro o bem individual eu consigo alcançar o bem coletivo. Sem a proteção da moradia o indivíduo não tem como ter segurança, trabalho, livre iniciativa etc.

Observa-se que não podemos trabalhar a tutela da moradia apenas sob o aspecto positivo, isto é, de prestação de políticas habitacionais pelo Estado, mas ela também é trabalhada sob a concepção negativa, no qual o Estado assegura o direito de moradia de inquilinos que vem cumprindo com o contrato de aluguel em caso de desentendimento com os locatários, por exemplo. Assim sendo, o direito de moradia, notadamente reconhecido como um direito social, tem um papel relevante dentro das funções do "Estado mínimo", vez que se está tutelando a liberdade individual.

O papel redistributivo, sendo considerado fato inevitável na sociedade, leva a crer na ressignificação da conceituação dos direitos do pensamento liberal, sendo hoje uma visão que vê sofrendo remodelagens para reconhecer o papel do Estado em uma abordagem mais atualizada da promoção da igualdade e da liberdade sob os chamados direitos fundamentais.

\subsection{DIREITOS SOCIAIS E A DESIGUALDADE NO DIREITO:}

A problemática questionada ainda sobre os direitos sociais pelos pensadores liberais cinge-se na alegação de desigualdade gerada sobre o Direito. Na medida que o Direito tem como função assegurar a manutenção da paz e esta, por sua vez, está ligada ao tratamento igualitário perante a lei, os liberais afirmam que os direitos sociais geram necessariamente fragmentações sociais ${ }^{4}$.

\footnotetext{
${ }^{4}$ Para mais informações ver: HAYEK, Friedrich A. Os fundamentos da liberdade. São Paulo: Visão, 1983, caps. 1 e 6; e NOZICK, Robert. Anarquia, Estado e utopia. São Paulo: Martins Fontes, 2011, prefácio, capítulos 1 e 7 a 9 .
} 
Todavia, partindo da superação da análise subdividida do conceito do direito em positivo ou negativo vê-se que o direito fundamental tem necessariamente o escopo de salvaguardar a igualdade ao máximo entre os indivíduos.

Dessa forma, o que para os pensadores liberais como Hayek e Nozick é visto como o desequilíbrio da igualdade formal a leitura do conceito de direito fundamental parte da ideia de "reigualar" as condições minimamente legítimas que naturalmente concernem a cada indivíduo como sendo parte integrante da sua liberdade individual. Por meio desse restabelecimento, mesmo que não de forma equânime, dos desníveis individuais naturalmente reconhecidos é que verdadeiramente alcança-se a igualdade perante o Direito.

Nesse sentido, explica Caridade Velarde que os direitos sociais têm a função de reforçar a proteção dos direitos individuais, na medida em que eles garantem minimamente um posicionamento menos desequilibrado dos indivíduos sem que isso afete ou restrinja o exercício da liberdade do ser (VELARD, 1994, p. 151). Por certo, é consensual que as diferenças sociais existiram, contudo, não é legítimo supor que o Estado mínimo de caráter não intervencionista garante a estes seres uma melhor condição e chances de exercerem suas potencialidades ao ponto de se encontrarem em melhores condições de vida do que se recebessem prestações sociais.

O direito de propriedade, reconhecido como um direito individual, é o primor dos direitos resguardados pelos liberais. O direito de moradia, sendo um direito social, tem se mostrado bem mais amplo que a proteção da propriedade em si, mas abraça aqueles vulneráveis ao ponto de tutelar também de forma mínima a segurança de um direito com viés individual.

Observa-se uma correlação muito forte entre direito de propriedade e moradia, muito embora não se confundam como dito. Nessa esteira, todos os demais direitos posteriores à $1^{\circ}$ geração vieram no sentido de aperfeiçoar ainda mais a efetividade da liberdade individual e não o contrário. Assim, reforça-se que o a figura do Estado mínimo, uma vez como para Nozick será a superação das associações de proteção, inevitavelmente pelo mesmo critério da antropologia será superado pela assunção do papel de reequilibrar os desníveis no que tange a segurança do exercício dos direitos individuais.

Percebe-se que aqui não se está defendendo um retomo de uma igualdade social perfeita, até porque essa pretensão violaria os valores que nascem da capacidade de outros indivíduos que conquistaram níveis sociais consideráveis. Todavia, há fatores externo a serem considerados como fontes limitatórias e que impedem os indivíduos de partirem dos mesmos parâmetros, tal como condição social (FUKASSAWA, 2013, p. 121). Sendo atualmente considerado normal essa diferença, mas na concepção dos pensadores liberais dever do Estado garantir sempre a tutela da liberdade, o que faz concluir que são pessoas que socialmente já estão tendo a sua liberdade violada assim que nascem, devido a sua condição social. 
Contudo, não se está adotando uma visão de John Rawls e sua justiça distributiva no qual cabe ao Estado oferecer a mesma oportunidade em uma dada instituição educacional de prestígio tanto aquele que pode pagar quando aquele que não poderia pagar (RAWLS, 2003, p. 81-83). Não é isso que se está defendendo. Deve buscar o Estado, por meio dos direitos sociais, o retomo dessa igualdade mínima, não deixando de fora aqueles indivíduos de poderem explorarem também a sua individualidade para fins de desenvolverem as suas propriedades e alavancarem com a progressão da civilização.

Desse modo, a assunção dos riscos não estaria sendo um problema a ser enfrentado pelo Estado, pois na medida em que age ofertando minimamente essas possibilidades pelos direitos sociais no final de tudo se está assegurando a todos a proteção da liberdade individual. Esta justificativa supera a sustentação dos pensadores liberais de que eu violo a igualdade quando alguns são privilegiados pelo Direito em relação a outros.

Do ponto de vista liberal se está considerando os direitos sociais como verdadeiros privilégios. Do ponto de vista da ressignificação para direitos fundamentais denota-se que não se tratam de privilégios, mas minimamente de se assegurar a todos a concretude da sua liberdade individual. O que nos fez considerar a ideia de trabalhar uma concepção de redistribuição mínima ou digna. Afinal, nem mesmo os próprios liberais conseguem se opor totalmente à condução civilizatória de redistribuição, sendo a adoção de restrições indiretas (conceito negativo de direito) um fundamento a ser superado.

É o que para Enzo Bello acontece no Brasil por meio da regularização fundiária. Na medida em que enfrentamos assentamos informais consolidados no tempo e no espaço não faz sentido haver a remoção destas pessoas, com fundamento na ausência de um direito de propriedade. Seguindo a concepção de Nozick esses indivíduos se ocuparam de terras não ocupadas e ou sem qualquer destinação, o que as torna legítimas proprietárias e carecem de proteção (BELLO, 2012, p. 224).

A proteção com base meramente no direito de propriedade as faria perder aquela ocupação. Portanto, o direito fundamental que legitima a regularização fundiária será o direito de moradia, vez que garantir a moradia, a ideia de habitação, reconhecimento da identidade cidadã daqueles indivíduos naquele lugar é garantir de forma mínima que aquelas pessoas possam dispor e se valer de suas propriedades para contribui com o desenvolvimento da civilização.

\subsection{DIREITOS SOCIAIS COMO PRESTAÇÃO DE SERVIÇOS:}

A visão dos direitos sociais como prestação de serviços e não como direitos propriamente dito é uma visão que muitos liberais compartilham. Dentre eles, Nozick sustenta que sob a ótica liberal viola a individualidade sustentar uma função estatal que inflija diretamente sobre a decisão 
das pessoas, particularmente falando em uma espécie de compensação com justificativa em cima do princípio da igualdade, que por sua vez é reclamada apenas sob o aspecto formal da legislação (EXDELL, 1977, p. 142-149).

Segundo Ronald Dworkin em seu discorrer sobre a teoria do direito considera os direitos fundamentais como sendo aqueles valores socialmente aceitos em sociedade e que justificam a validade de todo um sistema normativo de direitos (DWORKIN, 2012, p. 312). Os direitos sociais estão afastados dessa classificação, pois que para o pensador os direitos sociais não constituem direitos propriamente dito, sendo nada mais que meios para a efetivação de direitos individuais. Partindo dessa premissa, os direitos sociais não são considerados pressupostos de validade para o sistema normativo.

Nessa linha de pensamento é que Dworkin vai defender que direitos sociais são nada mais que políticas públicas. Contra esse posicionamento Norberto Bobbio vai fundamentar que os direitos sociais ganharam tamanho destaque pós $2^{\circ}$ guerra mundial, principalmente em um momento no qual há uma extrema preocupação com a universalização e abstrativização dos direitos humanos (BOBBIO, 1992, p. 58-60). Será então que, segundo o autor, direitos sociais passam a ser vistos como valores fundamentais que fazem parte de uma progressão histórica e social da humanidade, ao ponto dele próprio reclama ruma preocupação não mais com a positivação e a concretização de direitos jusnaturais, o que vem acontecendo ao longo dos séculos, mas sim de uma busca por meio de efetivar a concretude de tais valores.

Assim sendo, diferente de Ronald Dworkin, Norberto Bobbio vai defender a extrema necessidade de se pensar nos direitos sociais não apenas como meras prestações de serviços ou como política, mas sim como verdadeiros direitos, vistos não mais que a expansão dos direitos individuais e, considerando dessa forma, direitos fundamentais possíveis de estar presentes nas Constituições.

Considerando o aspecto acima e discorrendo sobre o direito de moradia Carlos Frederico Marés entende que minimamente os direitos sociais vieram como o outro lado da moeda dos direitos individuais que faltava para a completude dos valores fundamentais na humanidade (MARÉS, 2003, p. 22). Logo, pode-se afirmar que ao longo dos anos devemos reconhecer que o avançar da civilização trará a constituição de novos direitos, como podemos perceber hoje a evolução do direito tecnológico, do direito virtual, do direito climático etc. isso faz com que essa subdivisão de direitos em divisões, como deixa claro Norberto Bobbio, vá deixando de existir, pois a dinamicidade da sociedade faz necessariamente que o direito também se desdobre, mas sem perder a originalidade dos valores fundamentais (BOBBIO, 1992, p. 131).

Dessa forma, o direito de moradia deve ser encarado essencialmente como um valor fundamental, atrelado também à concretude do direito de liberdade de cada indivíduo na medida 
em que sem ela todos os demais direitos fundamentais individuais estão postos em risco. Pode-se inferir da ideia central do professor Daniel Sarmento que a regularização fundiária no Brasil (Lei federal $n^{\circ} 13.465$ de 2017) exemplifica bem o contexto de se resguardar a moradia em detrimento da mera concessão de títulos de propriedade (SARMENTO, 2004, p. 33).

Veja, não que se esteja afirmando que o direito de propriedade, como um direito individual de liberdade primordial, está sendo substituído. Na verdade, a propriedade constitui um direito essencial de liberdade e cabe ao Estado promover a sua proteção. Todavia, já há sustentos suficientes que levam a ver a concretização de direitos sociais como fenômeno que não prejudica ou infere na liberdade individual dos cidadãos, senão daqueles que estão em situação de informalidade e excluídos do contexto formal das urbes (SARMENTO, 2004, p. 37).

E na medida em que os próprios pensadores liberais não conseguem afastar totalmente a ideia de redistribuição de direitos em um contexto civilizatório, é mais racional avaliar um sistema de pensamento jurídico que ultrapassa a ideia de proteção da liberdade mínima por direitos negativos. Direito negativo também demandam custos, direitos positivos também demandam custos, ao final caberá ao Estado ter a função de redistribuir direitos da melhor forma possível para que todos possam usufruir livremente sem qualquer inferência de terceiros.

\section{CONCLUSÃO}

O presente estudo procurou abordar as principais características dos pensadores liberais Friedrich Hayek e Robert Nozick, delimitando seus principais fundamentos libertários de pensamento filosófico bem como o contraste entre a sua compreensão com o direito social.

Da análise comparativa deduziu-se uma necessidade de ultrapassar a separação entre direitos individuais de liberdade e direitos sociais. A conclusão por uma ressignificação da ideia de direito fundamental como sucessor desse pensamento classificatório mostra o reconhecimento legítimo do papel do Estado frente a concretização de verdadeiros valores fundamentais.

Nessa medida, ultrapassou-se a destinação da organização civil sob a manta do Estado mínimo. Em nenhuma medida se está defendendo um contexto de Welfare State. Ao contrário, a evolução dos Direitos Humanos tem comprovado que os direitos naturais, aqui entendidos sob a manta dos direitos que privilegiam a individualidade do ser humano, vem necessariamente se desdobrando em outros valores correspondentes que, ao final, estão interligados com os valores fundamentais da liberdade. Certamente, isso é bem presente na medida em que autores discorrem sobre a universalização e abstrativização de valores fundamentais no contexto mundial, e não mais local. 
Sob uma leitura dos pensadores liberais o direito de moradia, importante valor fundamental para a legislação brasileira, vem lutando contra um histórico de causa e efeito direito da proteção do direito de propriedade. Atualmente, a legislação brasileira, em especial a lei da Regulação Fundiária (Lei n ${ }^{\circ} 13.465$ de 2017) acaba justificando uma separação entre esses dois fundamentos, sem que isso importa na violação da liberdade individual.

Por isso, o direito de moradia constitui um exemplo significativo de estudo que prova a ressignificação dos direitos sociais meramente como prestações políticas ou de serviços. A moradia se apresenta muito mais como parte de um valor fundamental, que garante essencialmente o exercício da liberdade individual do ser, do que fator de desigualdade ou da involução da civilização. Tanto os direitos denominados aqui como negativos quanto os positivos demandam recursos, que em certa medida pode ser maior ou menor, mas não afasta a ideia de redistribuição como pressupostos imprescindível. De toda sorte, é possível coexistir os efeitos da redistribuição com a proteção da liberdade do indivíduo, garantindo-se a devida oportunidade, assunção de riscos em certa medida por todos e, finalmente, a progressão da civilização.

\section{REFERÊNCIAS BIBLIOGRÁFICAS}

BELLO, Enzo. A teoria política da propriedade na era moderna: ascensão e crítica do individualismo possessivo. Revista Quaestio Iuris, vol. 05, $\mathrm{n}^{\circ}$ 01, pp. 220-241, Rio de Janeiro, 2012. Disponível em: <https://www.e-publicacoes.uerj.br/index.php/quaestioiuris/article/view/ 9867/7729>. Acessado no dia 04 de abril de 2019.

BOBBIO, Norberto. A Era dos Direitos. Trad. Carlos Nelson Coutinho. Rio de Janeiro: Campus, 1992.

DWORKIN, Ronald. Justiça para ouriços. Coimbra: Almedina, 2012.

EXDELL, John. Distributive justice: Nozick on property rights. Ethics. Vol. 87. n. 2. (Jan. 1977) pp. 142-149.

FUKASSAWA, Fernando. Regularização fundiária urbana. São Paulo: Saraiva, 2013.

HAYEK, Friedrich A. Os fundamentos da liberdade. São Paulo: Visão, 1983.

Direito, legislação e liberdade: uma nova formulação dos princípios

liberais de justiça e economia política. v. I. Normas e ordem. São Paulo: Visão, pp. 218-268, 1985 , cap 5.

El atavismo da justicia social. Lima: Instituto de Economía de Libre Mercado, 1997. Originalmente em HAYEK, Friedrich A. New Studies in Philosophy, Politics, Economics and the History of Ideas. Chicago: University of Chicago Press, 1978. 
LACEY, A. R. Robert Nozick. Cesham: Acumen, 2001, pp. 20-72.

MALUF, Carlos Alberto Dabus. Limitações ao direito de propriedade. Revista da Faculdade de Direito, Universidade de São Paulo, v.106/107, jan/dez., pp. 839-855, 2011/2012. Disponível em: <http://www.revistas.usp.br/rfdusp/article/view/67968>. Acessado no dia 10 de junho de 2021.

MARÉS, Carlos Frederico. A função social da terra. Porto Alegre. Sergio Antonio Fabris Editor, 2003.

MIGOT, Aldo Francisco. A propriedade: natureza e conflito em Tomás de Aquino. Caxias do Sul: EDUCS, 2003.

NASCIMENTO, Mariana Chiesa Gouveia. Regularização Fundiária Urbana de Interesse Social no Direito Brasileiro. 2013. 189f. Dissertação de Mestrado em Direito - PPGD USP Universidade de São Paulo, São Paulo, 2013. Disponível em: $<$ https://teses.usp.br/teses/disponiveis/2/2134/tde-10012014-170104/publico/Dissertacao_Final _Mariana_Chiesa_Gouveia_Nascimento.pdf>. Acessado no dia 10 de junho de 2021.

NOZICK, Robert. Anarquia, Estado e utopia. São Paulo: Martins Fontes, 2011.

POGREBINSKI, Thamy; FERES JÚNIOR, João. Teoria política contemporânea: uma introdução. Rio de Janeiro: Elsevier, 2010, pp. 56-69.

RAWLS, John. Justiça como equidade: uma reformulação. São Paulo: Martins Fontes, 2003.

ROLNIK, Raquel. A cidade e a lei: legislação, política urbana e territórios na cidade de São Paulo. 2 ed. São Paulo. Studio Nobel: Fapesp. 1999.

SARMENTO, Daniel. Direitos Fundamentais e Relações Privadas. Rio de Janeiro: Lumen Juris Ed., 2004.

SCANLON, Thomas. Nozick on Rights, Liberty, and Property. In: JEFFREY, Paul. Reading Nozick: essays on Anarchy, State and utopia. Totowa, New Jersey: Rowman \& Allanheld, 1981, pp. 107-129.

VELARDE, Caridad. Hayek. Uma teoria de la justicia, la moral y el derecho. Madri: Civitas, pp. 149-204, 1994.

WOLFF, Jonathan. Robert Nozick: property, justice and minimal State. Stanford, California: Stanford University Press, 1991.

Trabalho recebido em 27 de outubro de 2021 Aceito em 01 de novembro de 2021 